\title{
The Organization of the Training of Technical College Students Using Practice-Oriented Tasks
}

\author{
Evgeny V. Politsinsky ${ }^{1} \&$ Larisa G. Demenkova ${ }^{1}$ \\ Yurga Institute of Technology of Tomsk Polytechnic University, Russia \\ Correspondence: Larisa G. Demenkova, Leningradskaya str., 26, Yurga, 652 055, Kemerovskaya area, Russia.
}

Received: June 14, 2014 Accepted: October 8, 2014 Online Published: December 2, 2014

doi:10.5539/ass.v11n1p187 URL: http://dx.doi.org/10.5539/ass.v11n1p187

\begin{abstract}
Physics and chemistry are the comprehensive basis for the training of a modern engineer. The most important type of learning activities for the students is to solve problems. The purpose of this paper is to generalize and systematize the experience of increasing the motivation of students of technical training areas for the study of fundamental scientific disciplines using practice-oriented tasks. We identified the following educational functions of teaching objectives: cognitive, developing, a feature of the unity of theory and practice, demonstration of interdisciplinary links, assessment of the quality of students' knowledge. This article describes the experience of using a practice-oriented task in the training of technical fields and specialties students, the stages of the developed method of teaching students to solve problem are described and substantiated. This method contains the following steps: 1) preparatory 2) developing an algorithm for problems of this type, 3) diagnostics and teaching them the unformed actions, 4) solving problems 5) control and reflective. In addition, the article provides guidelines for the organization of the students' activities for designing practice-oriented tasks It also gives the results of diagnosis of individual psychological characteristics of students personalities, which demonstrates not only an increase in their learning motivation, but also the broadening of their outlook, the growth of interest in life, in the future professional activity. It is shown that the practice-oriented approach makes it possible to successfully carry out activities to build students skills and abilities to solve problems, it also allows to increase their learning motivation, it favors the development of creative personality, which can be in demand in the labor market in the future. However, the main motives of choosing the profession changes: the cognitive and creative begin to dominate instead of the material and the level of succeed motivation increases.
\end{abstract}

Keywords: physics, chemistry, tasks, practice-oriented approach, learning motivation

\section{Introduction}

In the present socio-economic conditions, the effectiveness criteria of learning in higher school have cardinally changed: it is not only the professional knowledge and skills, but also certain individual and psychological personality qualities, that contribute to its' successful socialization and further professional growth (Verbitsky, 2009; Davletshina, 2011). University graduate should learn to analyze the ever-changing production situations; he should independently extract the necessary knowledge to solve them, to be always able to find his place in life. Consequently, the result of the educational process in the university should be not an individual with a specific set of knowledge, but a creative person who has a certain level of culture and scientific thinking. This level of culture can be formed only on the basis of scientific education, which has a wide and meaningful philosophical potential (Lattery, 2009). Physics and chemistry in the university is fundamental integrating disciplines and form the basis of comprehensive engineering education. It was noted that, without a deep knowledge of physics and other natural sciences the development of new technologies is impossible. (Redish, 2003). Therefore, science education is the key to further improvement of the quality of modern life. The most important and at the same time the most difficult type of learning activities in learning physics and chemistry is solving problems (Politsinsky \& Rumbeshta, 2006; Schmitt \& Lattery, 2004). In foreign pedagogy qualitative and computational tasks are widely used in teaching students physics and chemistry, especially for a better understanding of physical concepts, laws of physics and chemistry by the students (Gavrin, 2010; Redish, 2003; Schmitt \& Lattery, 2004). Most researchers noted that a number of students have troubles in solving problems during studying natural sciences (Neelam, 2011; Guisasola et al., 2010; Nguyen \& Rebello, 2009; Tobias \& Hake, 1988). The ability to solve problems - is a professional quality, required for each engineer on the one hand and is the best 
criterion for evaluating the depth of studying of the material - on the other. Analyzing the opportunities arising in the process of solving problems during the study of natural sciences, we can identify the main functions of the problems (Politsinsky, 2012):

- cognitive, through which we can significantly broaden the outlook of the students, using information assigned to improve students general cultural level (data about the life and work of scientists, interesting facts related to physical phenomena and chemical facilities);

- developing, which is to improve the skills of the students to work with different types of information (tables, directories, schedules, etc.), as well as the development of logical thinking, because such logic operations as analysis, synthesis, comparison, abstraction and generalization are used in solving problems

- the function of the unity of theory and practice, which is expressed in the formation of students' ability to use the laws of physics and chemistry to solve practical problems in their professional activity, as well as in everyday life;

- the function of demonstration of interdisciplinary communications of physics and chemistry in the first place - with math, as well as with the disciplines of special cycle;

- the function of quality assessment of students' knowledge. The correctness of the problem solving objectively reflects the level of mastering of educational material, provided by the program, as well as how the student knowingly possesses this material, how he uses it by himself. The discussed functions of tasks allow determining the importance of their use in the study of natural sciences.

\section{Methods}

In this paper, we used the following research methods: the study of psychological and pedagogical literature, which reveals the essence of the practice-oriented approach to learning; scientific methods of theoretical studies (analysis, synthesis, classification, modeling, abstraction, idealization, etc.); projective-experimental methods (design and modeling of pedagogical objects, experimental classes); diagnostic (questionnaire, survey, etc.) and empirical (the study of normative and methodological literature) methods; methods of collection, processing and presentation of the results of the experimental work (observation, survey, methods of mathematical statistics). During the work, the pedagogical experience of teaching physics and chemistry in a technical college was generalized, analyzed and systematized; we developed and proved a concept, psycho-pedagogical conditions and designed the necessary didactic tools for working with educational objectives; during the experimental work we revealed specifics of the formation of students' cognitive skills in didactic simulation environment.

In the process of teaching students problem solving, we used the method developed on the basis of active approach, which allows to obtain good results. This method contains the following steps: 1) preparatory, 2) developing an algorithm for problems of this type, 3) diagnostics and teaching them the unformed actions, 4) solving problems, 5) control and reflexive (Politsinsky \& Rumbeshta, 2006). Preparatory stage motivates students to solve problems. At this stage, the material is summarized by the students. At the stage of developing of the algorithm for such problems and at stage of their solving based on trial action to solve problems of a certain type, students themselves reveal the solving sequence, which ultimately leads to the identification of the solving algorithm. The teachers' work is to discuss with students the proposed algorithm, its correction and clarification. At the stage of diagnosis, on the basis of interviews with students, and the used questionnaires, the teacher determines the degree of mastery of some actions, which are needed to solve problems of this type. This stage in the future, during mastering the actions, which are necessary to solve problems of a particular type on this subject, may be excluded. Clarification of difficulties allows the teacher to organize an activity for the formation of separate actions, required to solve problems of this type. This is the content of the fourth stage. A study group is formed for mutual learning of the students solving problems of this type. At that, we use cards with tasks, that can be performed individually or in groups. In the group with a low level of cognitive and educational training, the teacher uses the system of tips, leading questions, and sometimes-detailed explanation of specific tasks. On the basis of diagnostic results we revealed students who have certain skills and abilities to deal with this type of problems, they combine with students, who don't have skills, or whose skills are not enough, to train them. After that, there is the fifth stage of problem solving. A work is organized in groups for independent solving of similar problems or their individual solving. On the estimating-reflexive stage, we can see generalization of the experience of acquiring skills, necessary to solve problems of this type, estimation and self-evaluation of the degree of development of the generalized ability to solve problems of this type. Then we use developed tasks, questionnaires, and check-reflective sheets. At this stage, the students assign the developed activity method. 


\section{Results}

As the results of diagnostic of the motivation of first year students' of technical training areas, conducted in YUTI TPU, the main motive of teaching at the beginning of the semester is to avoid punishment, i.e. the opportunity to receive a scholarship; at the end of the semester cognitive motives become the main motives for learning for most students. Using practice-oriented approach in the study of natural sciences, in our opinion, helped to achieve a higher motivation to learn chemistry, which is clear from the results of examinations in scientific disciplines: the average overall performance was $100 \%$, high-quality performance was $75 \%$. Moreover, $50 \%$ of students were actively engaged in teaching and research work, participated in national and international conferences and competitions. Students testing conducted at the end of the semester, showed that $100 \%$ of the respondents evaluated the knowledge of physics and chemistry as necessary for successful mastering of special disciplines, they notice outlook broadening during their study, as well as an increased level of motivation to succeed. Observation also confirms the growth of students' culture level. Moreover, the conducted study found that using of the proposed types of tasks affect the life-meaning orientations of the students, the interest to work increases, as well as the maturity of ideas and meaningful learning goals, which, in our opinion, helps to further successful socialization of first-year students in terms of technical university.

By experiment it has been captured 160 students of the first and the second year. The algorithm of activity of the student under the decision of any settlement problem (Table 1) and results of training (Figure 1) are presented below

Table 1. Algorithm of actions of the student at the decision of a settlement problem

\begin{tabular}{cc}
\hline Action & Result of action \\
\hline $\begin{array}{c}\text { Reading of a statement of the problem } \\
\text { Transformation of a statement of the problem to short } \\
\text { record and back }\end{array}$ & Understanding of condition \\
Analysis of information & Self-testing of understanding of condition \\
Application of settlement formulas & Way of the decision of a problem \\
Reflexion of actions and result & Correct answer \\
& Mastering of a way of the decision, formation of \\
logic thinking
\end{tabular}

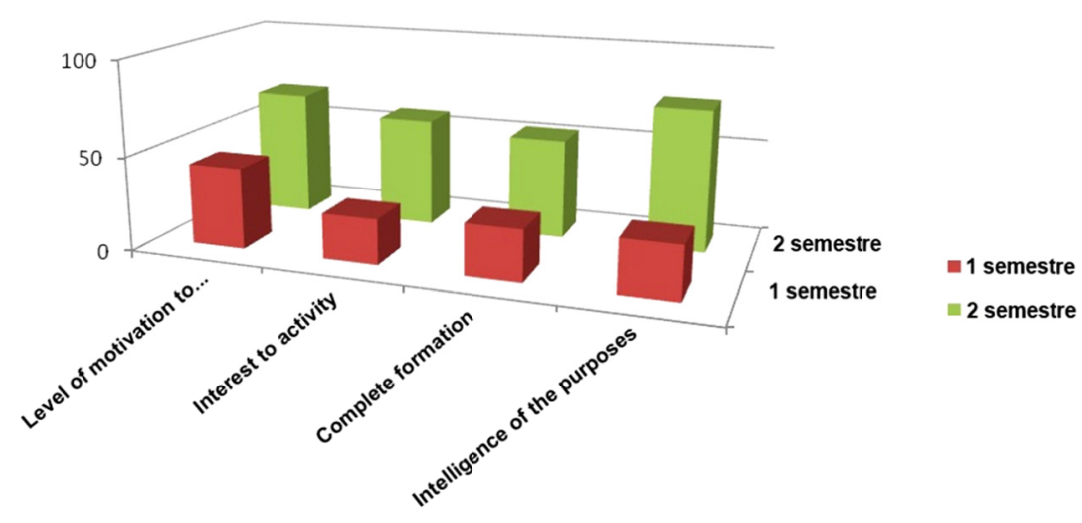

Figure 1. Dynamics of change of qualities of the person of students

Thus, we believe that the practice-oriented approach promotes the formation of a creative personality, which is able in the future to be in demand in the labor market.

\section{Discussion}

By analyzing data from surveying first year students of Yurga Technological Institute of Tomsk Polytechnic University (TPU YUTI), it was found that $72 \%$ of respondents have a low level of learning motivation to science, 
precisely because they have trouble in solving problems. It was found that $65 \%$ of students thereby experience a high level of anxiety. According to foreign researchers (Daryanavard et al., 2011), young people at this age are often prone to depression because of difficulties in learning. Data of input control showed that $80 \%$ of students have satisfactory knowledge and only $20 \%$ - good. Under these circumstances, the first priority in mastering physics and chemistry course was finding personal meaning of acquired knowledge, increasing learning motivation. Hazari et al., 2011 shows what exactly individual motivation is the driving force, which provides not only successful studying, but also further career growth. Motivational and necessary components of educational and professional activity have been studied by many domestic and foreign researchers (Verbitsky, 2009; Demenkova, 2014; Abootorabi, 2011; Pedditzi \& Spigno, 2012; Camp et al., 2010), and most of these works are about studying the influence of the teachers personality and the content of teaching and learning materials on the formation of learning motivation. Some authors (Verbitsky, 2009) believe that it is necessary to make extensive use of the possibility of context, or professional aimed training at mastering general disciplines. Foreign scientists believe that it is necessary to reform science education (Potter \& Lynch, 2012), while long since there is a need to increase its practical orientation (Watson et al, 1995). In addition, Meltzer, 2006 reveals the importance of integrating natural sciences with each other as well as with special disciplines. In our view, the problem of learning motivation can be solved by updating the content of the studied material by increasing its focus on practical activities, while maintaining a high academic level. We have analyzed the curricula of specialties and areas of training, and we defined disciplines of professional cycle, their successful assimilation is impossible without knowledge of the principles of natural science disciplines. For example, for the specialty 130400 "Mining" such disciplines are: "Geology", "material science", "mineral dressing", "Security of mining and mine rescue work", "Mining Ecology", "hydraulics", "Basics of researches, "" heat engineering "" Basics of Mining "," Technology and Security of blasting. " We designed assignments and tasks based on material of listed disciplines, which allowed implementing a practice-oriented approach to teaching physics and chemistry to students of this specialty. Examples of such tasks used in chemistry course for the specialty 130400 "Mining" on the subject "classes of inorganic compounds" could be the next task: to determine what class of chemical compounds do the following ore minerals belong to: magnetite, or lodestone $\mathrm{Fe}_{3} \mathrm{O}_{4}$; hematite, or bloodstone $\mathrm{Fe}_{2} \mathrm{O}_{3}$; siderite, or black band $\mathrm{FeCO}_{3}$. Give them names IUPAC. Which reaction can determine that the ore mineral is a carbonate? For comparison we present one of the tasks that are used on a same lesson with students, who study in the area 110800 "Agro engineering": ammonium sulfate, potassium chloride, ammoniac, calcic and sodium niter is used as a fertilizer in agriculture. Make their chemical formulas, and give the reactions by which one can prove the qualitative composition of the listed substances.

Here are the following examples of tasks that use a practice-oriented approach $n$ teaching physics for students of training areas 150700 «mechanical engineering»:

a) A crane in the mechanical shop vertically raised a container with products that have $500 \mathrm{~kg}$ in weight to a height of $4 \mathrm{~m}$ with a constant force. During this a work of $20 \mathrm{~kJ}$ was performed. Calculate the acceleration the load was left with;

b) During the work of chuck-and-shaft lathe at elevated temperature, inert gas neon is used in its pneumatic actuator, which heats at a low pressure of $55 \mathrm{kPa}$. This increases the volume of $6 \mathrm{~m} 3$ to $3 \mathrm{~m} 3$. Determine the change in internal energy of neon; work performed during expansion; The amount of heat given to the gas;

c) When processing a steel part weighing $3 \mathrm{~kg}$ on a thread-cutting lathe lathes the temperature of the parts increased by $150 \mathrm{~K}$. water based cutting fluid is used for cooling the part. Meanwhile, the fluid increases its temperature at $15 \mathrm{~K}$. Determine how much fluid is required for cooling the part?

d) In welding fabrication they use electrodes of the brands MP-3 and UONI-13/45, modified by the introduction of titanium nanopowder by cavitations (Makarov \& Sapozhkov, 2013). Calculate the molar concentration of the nanopowder, if 300 grams of titanium are dissolved in 15 liters of sodium silicate.

In addition, we have developed tasks with the use of information that may be needed in everyday life. In everyday life man faces a lot of chemicals, and each student must have at least a minimal understanding of how to handle them. An example of such a problem: in order to give the food a sour taste they often use acetic acid $\mathrm{CH}_{3} \mathrm{COOH}$, which is a weak electrolyte. Write down the equation of dissociation of the acid. Using the reference data of the dissociation constant, calculate the pH of $0.2 \mathrm{M}$ of the acetic acid solution, and the degree of dissociation.

An example of a quality problem, based on the use of physical knowledge in everyday life, is the following problem: why the spirals of electric heaters are made of materials with high resistivity? The tasks we use allow us to generate interest among students, thereby increasing learning motivation. 
We should notice that constructing problems in physics and chemistry provokes a great interest among students. This activity accumulates all other types of educational and research activity when working with tasks; it is a creative process with a high developmental effect. In addition, this type of activity serves as an effective means that ensures the integration of subject, interdisciplinary and methodological knowledge and skills. These activities includes: choosing the problem situation; its analysis (selection of objects and subjects of investigation); formulation of requirements; selecting information basis; solving the problem; analysis of the result and correction of terms. Designing of physical problems and problems in chemistry can be organized when working in groups directly during class, followed by discussion, analysis of results and joint correction, as well as independent homework.

\section{Conclusion}

An important limitation of this study is that we studied the results of a practice-oriented approach in teaching only two natural sciences - physics and chemistry, as well as students of one technical college. Beyond this work remained such important issues as the effect of this approach on the effectiveness of the learning process achieving results with minimal time and energy of the students, as well as education issues that take into account the potential abilities and age psycho physiological characteristics of the students, their aptitude for subject professional activity. Furthermore, we should examine the results of applying a practice-oriented approach to teaching mathematics. Further studies will be taken in this direction.

\section{References}

Abootorabi, R. (2011). How I could improve academic motivation of my students in an industrial high school? Proceedings - Social and Behavioral Sciences, 15, 571-575.

Camp, M. E., Middendorf, J., \& Sullivan, C. S. (n. d.). Using Just-in-Time Teaching to Motivate Student Learning. Just-in-Time Teaching. Across the Disciplines, Across the Academy. Published in Association with The National Teaching and Learning Forum (pp. 25-34).

Daryanavard, A., Madani, A., Mahmoodi, M. S., Rahimi, S., \& Nourooziyan, F. (2011). Prevalence of depression among high school students and its relation to family structure. Am. J. Applied Sci., 8, 39-44. http://dx.doi.org/10.3844/ajassp.2011.39.44

Davletshina, L. A. (2011). Social mechanisms of interaction between universities and employers in terms of monoprofile city. News of higher educational institutions. Volga region. Social Sciences, 3(19), 82-88.

Demenkova, L. G. (2014). Professionally-oriented teaching of chemistry in a technical college. Prospects for the development of science and education: A collection of scientific papers based on the International scientific-practical conference: in 15 parts. Ch 4, Tambov. Tambov Business Science-Society (pp. 31-32).

Demenkova, L. G. (2014). Professional and student-centered learning of chemistry. The potential of modern science, 1, 107-111.

Gavrin, A. D. Using Just-in-Time Teaching in the Physical Sciences. Just-in-Time Teaching. Across the Disciplines, Across the Academy. Published in Association with The National Teaching and Learning Forum (pp. 117-127).

Guisasola, J., Zubimendi, J. L., \& Zuza, K. (2010). How much have students learned? Research-based teaching on electrical capacitance. Physical review ST-Education Research, 6. http://dx.doi.org/10.1103/PhysRevSTPER.6.020102

Hazari, Z., Potvin, G., Tai, R., \& Almarode, J. (2010). For the love of learning science: Connecting learning orientation and career productivity in physics and chemistry Phys. Rev. ST Phys. Educ. Res., 6(1).

Lattery, M. J. (n. d.). Signature pedagogies in introductory physics. Exploring signature pedagogies: Approaches to teaching disciplinary habits of mind (pp. 280-295).

Lin, Sh.-Y., \& Singh, Ch. (2011). Using isomorphic problems to learn introductory physics. Physical review special topics. Physics education research, 7(2). http://dx.doi.org/10.1103/PhysRevSTPER.7.020104

Makarov, S. V., \& Sapozhkov, S. B. (2013). Use of Complex Nanopowder $\left(\mathrm{Al}_{2} \mathrm{O}_{3}, \mathrm{Si}, \mathrm{Ni}, \mathrm{Ti}, \mathrm{W}\right)$ in Production of Electrodes for Manual Arc Welding. World Applied Sciences Journal, 22, 87-90.

Meltzer, D. (2006). Investigation of Student Learning in Thermodynamics and Implications for Instruction in Chemistry and Engineering. PERC Proceedings (pp. 38-41).

Neelam, Kh., Hu, D., Nguyen, D.-H., \& Rebello, N. S. (2009). Students'Difficulties in Transfer of Problem Solving Across Representations. Physics Education Research Conference, Ann Arbor. MI. 
Neelam, Kh., Hu, D., Nguyen, D.-H., \& Rebello, N. S. (2011). Assessing students' ability to solve introductory physics problems using itegrals in symbolic and graphical representations. Physics Education Research Conference, 1413, 227-230. Omaha, Nebraska.

Pedditzi, M. L., \& Spigno, M. (2012). Motivation to learn: a research on university students. Procedia - Social and Behavioral Sciences, 69, 1198-1207. http://dx.doi.org/10.1016/j.sbspro.2012.12.052

Politsinsky, E. V. (2006). Implementation of the activity approach in teaching pupils solving physics problems. Herald TSPU. Series: Natural and exact sciences, 6(57), 164-168.

Politsinsky, E. V. (2012). Learning technique for solving problems in physics: The implementation of the activity approach in teaching pupils and students solving physics problems. Monograph. Publ: LAP LAMBERT Academic Publishing GmbH \& Co. KG, Germany (p. 274).

Potter, W., \& Lynch, R. (2012). Additional Evidence of Far Transfer of Scientific Reasoning Skills Acquired in a CLASP Reformed Physics Course PERC Proceedings (pp. 314-317).

Redish, E. F. (2003). Teaching Physics with the Physics Suite. Hoboken, NJ: John Wiley and Sons.

Schmitt, J., \& Lattery, M. (2004). Facilitation discourse in the physics classroom. NCREL Annual Conference. Retrieved February 12, 2014, from www.planck.phys.uwosh.edu/lattery/_docs/art_mm_fac.pdf.

Tobias, S., \& Hake, R. (1988). Professors as physics students: What can they teach us? Am. J. Phys., 56(786).

Verbitsky, A. A. (2009). Personal and competence approach in education: Problems of integration. Logos, Moscow (p. 336).

Watson, R., Prieto, T., \& Dillon, J. (1995). The Effect of Practical Work on Students' Understanding of Combustion, Journal of Research in Science Teaching, 32(5), 487-502. http://dx.doi.org/10.1002/tea. 3660320506

\section{Copyrights}

Copyright for this article is retained by the author(s), with first publication rights granted to the journal.

This is an open-access article distributed under the terms and conditions of the Creative Commons Attribution license (http://creativecommons.org/licenses/by/3.0/). 